\title{
TOWARDS OPTIMAL MENTAL HEALTH OF PERSONS WITH DOWN SYNDROME
}

\author{
Siegfried M. Pueschel, MD, PHD, JD, MPH \\ Child Development Centre Rhode Island Hospital Brown University \\ School of Medicine Providence, Rhode Island
}

\begin{abstract}
This paper outlines the risk of mental health disorders in adults with Down syndrome and considers the practical ways in which positive well-being can be promoted. It emphasises that prevention begins at birth and parents need to be alerted to positive child-rearing strategies from infancy.
\end{abstract}

Keywords: Mental health, adults, adolescents

\section{Introduction}

Numerous previous reports indicate that there is a high prevalence of psychiatric disorders and behaviour problems in persons with Down syndrome. Cuskelly and Dadds (1992) noted that children with Down syndrome display more behaviour problems and show significantly more attentional concerns than their siblings.

Concerning psychiatric disorders, Menolascino (1965) reported that 11 of $86(13 \%)$ children in his study had psychiatric conditions. A study by Gath and Gumley (1986) revealed that 73 of 193 (38\%) children and adolescents with Down syndrome displayed psychiatric disorders. In another investigation, Lund (1988) observed that $25 \%$ of persons with Down syndrome had psychiatric problems. Myers and Pueschel (1991) examined 497 persons with Down syndrome and found the overall prevalence of psychiatric disorders to he $22.1 \%$. These authors noted a wide range of psychopathology in persons with Down syndrome including major depressions, obsessivecompulsive disorders, anorexia nervosa, phobias, conversion reactions, paraphilias, eating disorders and others. From these and other studies, it is apparent that persons with Down syndrome may be at a higher risk for behaviour and psychiatric disorders when compared with a normal population.

The question arises whether is it feasible to prevent, at least in part, certain behavioural and psychiatric conditions in individuals with Down syndrome? Although no long-term studies have investigated this question, there are a number of considerations that will he detailed in the following discussion that could lead to a better mental health in persons with Down syndrome.

\section{The importance of a positive approach to counseling parents}

Learning that their infant has Down syndrome is an extremely traumatic experience for the parents. Most parents who have lived through such a crisis describe sensations of overwhelming shock and disbelief. What was anticipated as a joyous event has turned into a catastrophe. During this initial period of shock, many parents will display a wide variety of emotional responses including anger, inadequacy, shame, and disappointment. Cognitive dysfunction and a disturbance of personality integration are often observed in the distressed parents. Parents do not know what the future may hold for their child. The feelings of helplessness and emotional disorganisation usually last for a number of days, in some parents even weeks, depending on the individual parent's emotional strengths, maturity, religious convictions, and previous life experiences. For many parents, however, the sadness and the depressed feelings may take a long time to fade.

During this initial crisis, the physician should provide optimal counselling and genuine support for the traumatised parents. This difficult task 
demands tact, wisdom, compassion, and truthfulness. The physician should communicate his/her message sympathetically and supportively. His/her approach will greatly influence the parents' attitude and subsequent adjustment. It will set the tone for the atmosphere that will prevail in future years. The physician who emphasises that the child with Down syndrome is first and foremost a human being who needs the love of caring parents will pave a positive way for this child's future. Parents need hope and encouragement to see positives in their child. The physician should attempt to identify and mobilise emerging parental strengths.

If parents are counselled appropriately during the initial time period, their mental well-being will be enhanced. They will be able to cope better and this in turn should have a beneficial effect on the child's emotional development.

Beyond the very traumatic, emotional experience surrounding the child's birth, there may he subsequent stress situations. As the child grows, he/she will pass through a series of developmental stages and experiences such as entering school or engaging in vocational activities.

With each stage, parental patterns of coping may reactivate unresolved issues from the past. In such situations, the parents may be in need of support and guidance by the caring professionals. If parents are provided with the appropriate assistance and counselling, they will cope more effectively and their child's mental health will be enhanced.

\section{Strategies for improving mental health in people with Down syndrome}

\section{Discipline, rules, and limits}

All children including youngsters with Down syndrome will require some form of discipline. Clearly defined rules and limits will need to be established in the upbringing of the child with Down syndrome as for any other child. Rules give order and substance to the environment and limits define the line between what is and what is not acceptable. Parents need to establish certain limits in order to help their child with Down syndrome to learn behaviours that are appropriate. In setting up rules and providing discipline, parents should display positive interactions with the child. Children have to receive positive messages about themselves and what they do. Children thrive on positive reinforcement of good behaviour. Many behaviour problems can be avoided if such an approach is used in the rearing of children with Down syndrome.

\section{Developing self-competence and self- esteem}

It has been emphasised that the family atmosphere and parenting practices are major factors underlying the development of self-competence in the child (Powers and Sikora 1997). Mink, Nihira, and Meyers (1983) reported that family conditions that are high in cohesion and relatively low in conflict, where there exists a high level of involvement and pride in children such circumstances will help the child develop a high self-esteem and lead to a positive psychosocial adjustment. Powers, Zinger, and Todis (1996) as well as Ferguson and Asch (1989) underline the importance of parents focusing on the children's strengths. According to Powers and Sikora (1997), parenting practices that promote self-competence include:

1. positive supportive interaction,

2. providing opportunities to practice and develop autonomy,

3. focusing on the individual's strengths,

4. providing accommodation to reduce the restrictiveness of disability, and

5. using reasoning and limit-setting.

The development of certain skills are important for the expression of self-competence. Powers et al. (1996) indicate that the self-competence of youngsters with Down syndrome can be enhanced through the acquisition and application of specific achievement, partnership, and coping skills. In addition, an important skill for expressing selfcompetence is goal setting (Gardner, 1986). Other essential skills for developing self-competence are problem-solving, assertiveness, self-advocacy, selfmonitoring, frustration management, access to support by others, and the development of friendships (Powers and Sikora, 1997). Thus, in fostering self-competence, persons with Down syndrome will feel better about themselves which again will enhance their mental health.

\section{Self-determination}

Self-determination assumes that individuals with

Down syndrome have a greater control over decision and resources (Nisbet, Crowley, and Crowley, 1997). Self- determination is a concept that can provide direction for families and human service professionals. Self-competence, selfesteem, and self-determination that can bring about mental well-being should be fostered in the home environment, in the educational and vocational settings, as well as in the community by and large. 


\section{Promoting recreational activities \\ Heyne and Schleien (1994) stressed the} importance of developing leisure repertoires that will teach individuals with Down syndrome to learn new skills, and strengthen their physical and mental well-being. On the other hand, the absence of a meaningful leisure program will foster maladaptive or aggressive behaviours (Wehman and Schleien 1981). Successful involvement in recreational skills will enhance the self-confidence and the self-esteem in many people with Down syndrome. Heyne, Schleien, and Rynders (1997) point out the significance of leisure education and the importance of physical activities which will expand the social network, promote friendships, and introduce a sense of autonomy.

Songster et al. (1997) emphasise that consistent training and sports competition in Special Olympics are essential to the physical, mental, and social developments of young people with Down syndrome. The benefit of such training and competition stimulates self-confidence and promotes acceptance by society. Individuals with Down syndrome participating in Special Olympics activities have been inspired to celebrate the unlimited potential of the human spirit by sharing the skill, courage, and joy expressed in the lives of the athletes (Songster et al., 1997) There are many other activities people with Down syndrome can in engage in that will promote self-confidence, selfworth, and a greater self-esteem. For example, martial arts, dancing, hiking, bicycling, gymnastics, and just having plain fun all of which can lead to a better mental well-being of the person with Down syndrome.

\section{Treatment modalities}

In spite of the various preventive measures and positive approaches described above, and in spite of assisting the young person with Down syndrome to achieve optimal physical and mental health, there may be situations where an individual with Down syndrome may display aberrant behaviors or is found to have a psychiatric disorder. If significant behaviour problems become apparent, professional help may be necessary. There are various strategies for behaviour management as detailed by Cuskelly and Gunn (1997) including self-regulation, appropriate positive reinforcement, and other behaviour modification approaches. Often a close collaboration of counsellor, school personnel, parents, and other caregivers will benefit the person with Down syndrome. If a person with Down syndrome has been diagnosed with a specific psychiatric disorder, then the person may be in need of specific psychotropic medications and/or psychotherapy and parental counselling should be provided. Although proactive prevention is of primary importance, those children who are exhibiting behaviour or psychiatric disorders should be treated effectively so that they will he able to interact well with other people in the community and will enjoy a good quality of life.

\section{Conclusion}

If at the birth of their child with Down syndrome, parents are appropriately counselled and if they are provided with positive guidance, most of them will be able to adjust and cope well. Parents then will be able to foster the child's optimal physical and mental well-being. It is important that the person with Down syndrome can live in a nurturing environment that promotes self-confidence and self-esteem and avoids undue stressful situations. There are numerous leisure activities as detailed above persons with Down syndrome can become involved in that will result in a well- adjusted lifestyle and should ultimately lead to optimal mental well-being. If an individual with Down syndrome should exhibit a severe behaviour or psychiatry disorder, professional help and appropriate treatment should be forthcoming. In order to live a happy, well-adjusted life and to be able to contribute to society, persons with Down syndrome should be offered a status that observes their rights and privileges as citizens in a democratic society and, in a real sense, preserves their human dignity. 


\section{References}

Cuskelly, M. and Dadds, M. (1992). Behavioural problems in children with Down's syndrome and their siblings. Journal of Child Psychology and Psychiatry and Applied Disciplines, 33, 749-761.

Cuskelly, M. and Gunn, P. (1991). Behaviour problems in adolescents with Down syndrome. In C.J. Denholm (Ed), Adolescents with Down syndrome: International Perspectives on Research and Programme Development. pp. 53-61. Victoria, British Columbia, Canada: University of Victoria.

Ferguson, P. M. and Asch, A. (1989). Lessons from life: Personal and parental perspectives on school, childhood and disability. In D. Biklen and D. Ferguson, and A. Ford (Eds), Schooling and disability pp. 108-140. Chicago: University of Chicago Press.

Gardner, N.E.S. (1986). Sexuality. In J.A. Summers (Ed.), The right to grow up: An introduction to adults with developmental disabilities, pp. 45-66. Baltimore: Paul H. Brookes Publishing Co.

Gath, A. and Gumley, D. (1986). Behaviour problems in retarded children with special reference to Down's syndrome. British Journal of Psychiatry, 149, 156-161.

Heyne, L. and Schleien, S. (1994). Leisure and recreation programming to enhance quality of life. In E. Cipani and F. Spooner (Eds.), Curricular and instructional approaches for persons with severe disabilities, pp. 213-240. Boston: Allyn and Bacon.

Heyne, L.A., Schleien, S.J. and Rynders, J.E. (1997). Promoting quality of life through recreation participation. In S.M. Pueschel and M. Sustrova (Eds.), Adolescents with Down Syndrome, pp. 317-340 Baltimore: Paul H. Brookes Publishing Co.

Lund, J. (1985). The prevalence of psychiatric morbidity in mentally retarded adults. Acta Psychiatrica Scandinavica, 72, 563-570.

Mink, I.R., Nihira, K., Myers, C.E. (1983). Taxonomy of family life styles: I. Homes with TMR children. American Journal of Mental Deficiency, 87, 484-497.

Myers, B.A. and Pueschel, S.M. (1991). Psychiatric disorders in a population with Down syndrome. Journal of Nervous and Mental Disease, 179, 609-613.

Nisbet, J.A., Crowley, T. and Crowley, N. (1997). Community support and participation. In S.M. Pueschel and M. Sustrova (Eds.), Adolescents with Down syndrome, pp. 301-312. Baltimore: Paul I-I. Brookes Publishing Co.

Powers, L.E. and Sikora, D.M. (1997). Promoting adolescent self-competence. In S.M. Pueschel and M. Sustrova (Eds.), Adolescents with Down Syndrome. pp. 71-89. Baltimore: Paul H. Brookes Publishing Co.

Powers, L,.E., Turner, A., Wilson, R., Matuszewski, J., Ellison, R. and Rein, C. (1995). A controlled fieldtest of the efficacy of a multi-component model for promoting adolescent self determination. Lebanon, $\mathrm{NH}$. Hood Center for Family Support. Dartmouth Medical School.

Songster, T.H., Smith, G., Evans, M., Munson, D. and Behen, D. (1997). Special Olympics and athletes with Down syndrome. In S.M. Pueschel and M. Sustrova (Eds.), Adolescents with Down Syndrome, pp. 341-357. Baltimore: Paul H. Brookes Publishing Co.

Wehnian, P. and Schleien, S. (1981). Leisure programs for handicapped persons: Adaptations, techniques and curriculum. Austin, TX: PRO-ED. 